\title{
Tracheal rupture after endotracheal intubation - A report of three cases -
}

\author{
Hyungsun Lim, Jung Hee Kim, Deokkyu Kim, Jeongwoo Lee, Ji Seon Son, Dong Chan Kim, and \\ Seonghoon Ko
}

Department of Anesthesiology and Pain Medicine, Chonbuk National University Medical School, Jeonju, Korea

Tracheal rupture is a rare but serious complication that occurs after endotracheal intubation. It usually presents as a linear lesion in the membranous wall of the trachea, and is more prevalent in women and patients older than 50 years. The clinical manifestations of tracheal injury include subcutaneous emphysema and respiratory distress. We report the cases of three female patients of old age presenting tracheal rupture after endotracheal intubation. Two cases received surgical repair without complication and one recovered uneventfully after conservative management. We presume that the tracheal injuries were caused by over-inflation of cuff and sudden movement of the tube by positional change. Therefore, we recommend cuff pressure monitoring during general anesthesia and minimized movement of the head and neck at positional change. (Korean J Anesthesiol 2012; 62: 277-280)

Key Words: Airway, Intubation, Rupture, Subcutaneous emphysema, Trachea.

Tracheal rupture is a rare but life-threatening complication that most commonly occurs after blunt trauma of the neck and chest [1]. Tracheal rupture after endotracheal intubation is extremely rare, with a reported incidence of approximately $0.005 \%$ [2]. A multi-factorial origin of rupture has been proposed, with important roles for mechanical, anatomical, and individual factors, many of them still undefined [3]. We report three cases of tracheal rupture related to tracheal intubation under general anesthesia.

\section{Case Reports}

All three cases were transferred to our hospital after elective spine surgery under general anesthesia in a local hospital. The anesthetic techniques during spine surgery of three cases were the same. After induction of anesthesia with propofol and vecuronium, orotracheal intubation was performed without any difficulty (Cormack 1, 1st attempt) using a single lumen internal diameter (ID) $7.0 \mathrm{~mm}$ cuffed reinforced tracheal tube (Mallinckrodt Medical, Athlone, Ireland) by an experienced anesthesiologist. The stylet was removed when the tube was passed through the vocal cord. Anesthesia was maintained with sevoflurane in $\mathrm{N}_{2} \mathrm{O} / \mathrm{O}_{2}\left(\mathrm{FiO}_{2}=0.5\right)$. Spine surgery proceeded without a specific event in prone position. At the end of the surgery, the endotracheal tube was removed when the patient responded to verbal commands and showed sufficient

Received: May 11, 2011. Revised: July 23, 2011. Accepted: July 27, 2011.

Corresponding author: Seonghoon Ko, M.D., Ph.D., Department of Anesthesiology and Pain Medicine, Chonbuk National University Medical School, 634-18, Geumam-dong, Deokjin-gu, Jeonju 561-712, Korea. Tel: 82-63-250-1979, Fax: 82-63-250-1240, E-mail: shko@jbnu.ac.kr (c) This is an open-access article distributed under the terms of the Creative Commons Attribution Non-Commercial License (http:// creativecommons.org/licenses/by-nc/3.0/), which permits unrestricted non-commercial use, distribution, and reproduction in any medium, provided the original work is properly cited. 
spontaneous respiration. Blood was not tinged on the extubated endotracheal tube. The duration from intubation to extubation was 170, 215 and 185 minutes, respectively, for the three cases.

\section{Case 1}

A 77-year-old woman (height, $150 \mathrm{~cm}$; weight, $50 \mathrm{~kg}$ ) received spine surgery under general anesthesia in a local hospital. No other medical history and specific abnormal laboratory results were recorded except the arterial hypertension for about 20 years.

On postoperative day 2, the patient complained of discomfort on the anterior chest and neck with dyspnea. The chest $\mathrm{X}$-ray showed pneumomediastinum and subcutaneous emphysema. The patient was then referred to our hospital. A computed tomography (CT) scan of the chest visualized the injury of the posterior tracheal wall due to the rupture of the pars membranosa (Fig. 1).

An emergent operation was decided, and was initiated as induction of anesthesia by propofol and remifentanil target controlled infusion (TCI). Before tracheal intubation, a fiberoptic bronchoscopy revealed a longitudinal hole with sharp margins at the posterior part of the membranous portion, with a total length of $6 \mathrm{~cm}$ approximately $3 \mathrm{~cm}$ from the carina. Tracheal intubation was performed by 35 Fr double lumen tube for one lung ventilation. Tracheal laceration was repaired without any specific event.

\section{Case 2}

A 52-year-old woman (height, $158 \mathrm{~cm}$; weight, $60 \mathrm{~kg}$ ) underwent spine surgery due to spinal stenosis at the same hospital as case 1 . She was transferred to our ER due to dyspnea and subcutaneous emphysema approximately 3 hours after the

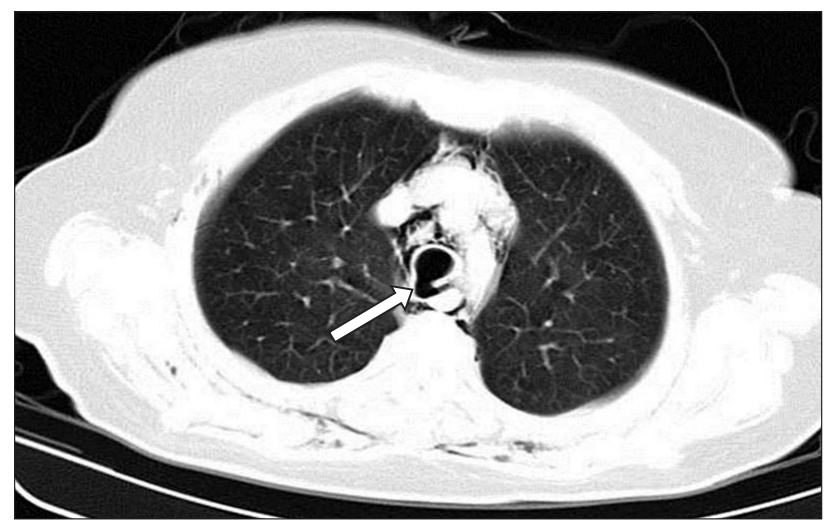

Fig. 1. Chest CT showing the injury of the posterior tracheal wall and pneumomediastinum due to the rupture of the pars membranosa (arrow). operation.

Her medical history was recorded as arterial hypertension and diabetes 18 years ago, and she was treated by administration of angiotensin receptor antagonist and insulin pump. When she was admitted at our hospital, pneumomediastinum, subcutaneous emphysema and pneumothorax were found on chest X-ray (Fig. 2) and chest CT. Bronchoscopy confirmed a linear laceration of 3-4 cm in length on the posterior membranous wall of the mid-trachea (Fig. 3). An operation was decided after chest tubing on the left side.

Anesthesia was induced by propofol and remifentanil TCI, and tracheal intubation was taken by an ID $7.5 \mathrm{~mm}$ reinforced tube through the injured mid-trachea. The tube was advanced into the left main bronchus by fiberoptic bronchoscopy for one

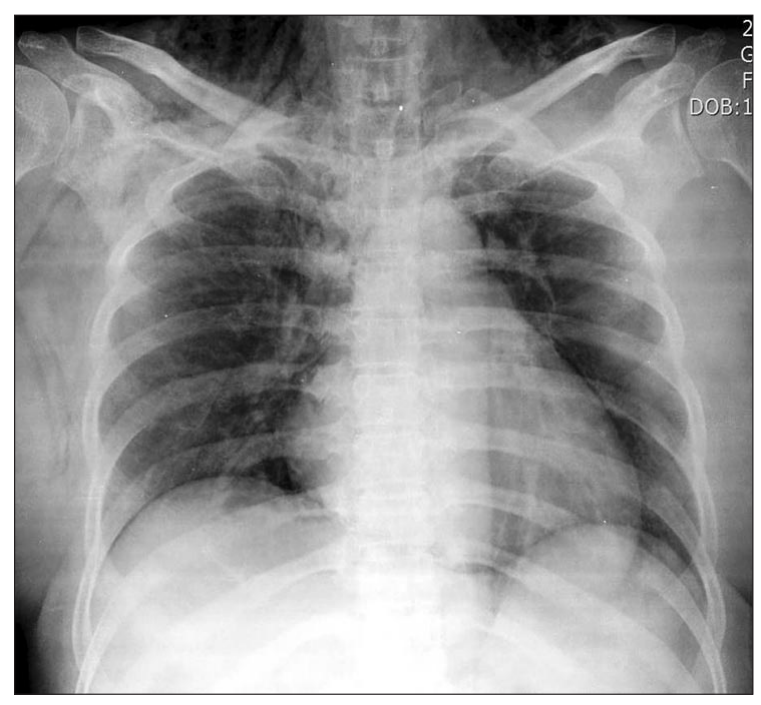

Fig. 2. A chest X-ray in the posteroanterior view showing pneumomediastinum, subcutaneous emphysema and pneumothorax.

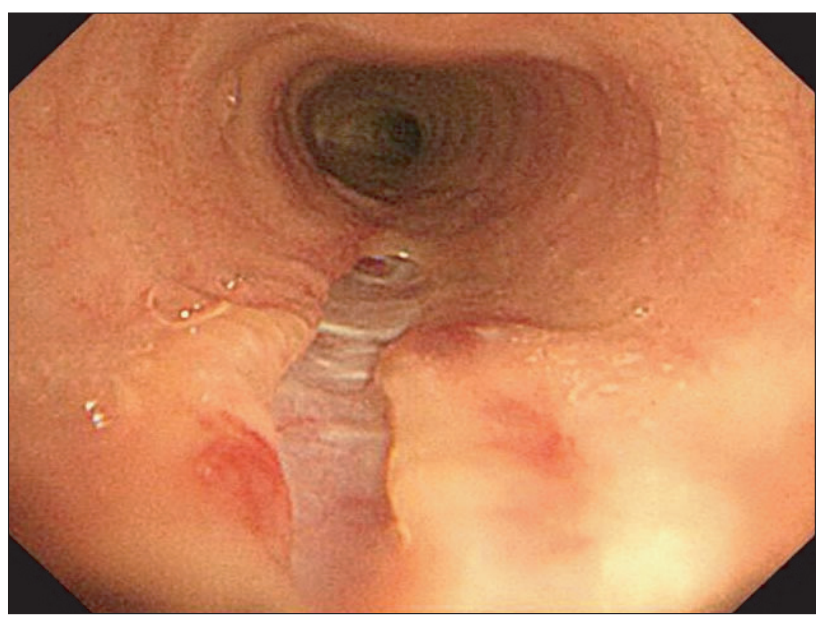

Fig. 3. Diagnostic bronchoscopy revealing a linear laceration of 3-4 $\mathrm{cm}$ in length on posterior membranous wall of mid-trachea. 


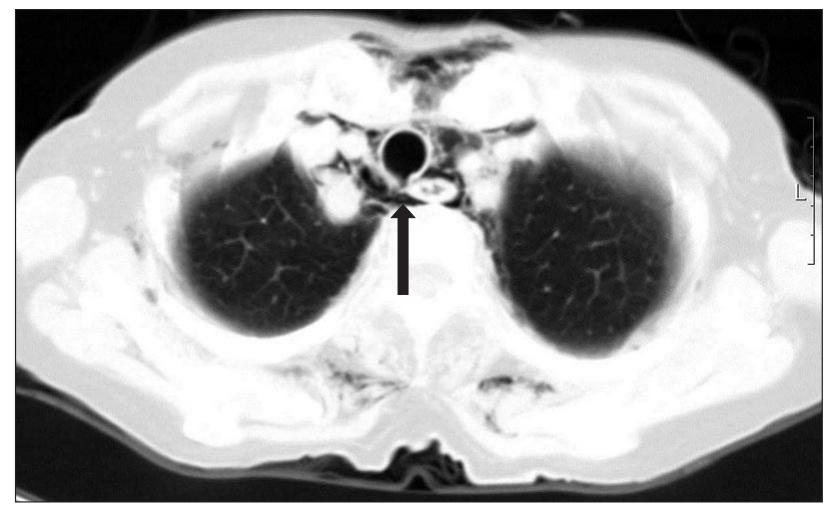

Fig. 4. Chest CT showing a laceration on the posterior membranous wall of mid-trachea (arrow).

lung ventilation after the operation had begun. The trachea was repaired successfully, and the patient was discharged in good condition from the hospital.

\section{Case 3}

A 73-year-old woman (height, $153 \mathrm{~cm}$; weight, $53 \mathrm{~kg}$ ), who underwent spine surgery at the same hospital as case 1 and 2, had mild subcutaneous emphysema on postoperative day 2 . Pneumomediastinum and subcutaneous emphysema were presented on chest X-ray. Chest CT revealed a laceration on the posterior membranous wall of the mid-trachea (Fig. 4). However, the patient's symptoms were mild enough to recover by close observation with conservative treatment.

\section{Discussion}

There are multiple factors that contribute to this type of injury. These factors may be divided into mechanical factors that include trauma during intubation, overinflation of the cuff and vigorous coughing etc., and anatomical factors [4]. Overinflation of cuff and sudden movement of the tube are the two most common reasons, and direct tear caused by the tube itself is rare [5]. We suspect that the cause of tracheal injury is overinflation of the cuff because of the following reasons. Although the cause of tracheal rupture may be an injury by stylet or tube tip, endotracheal intubation was not difficult at all in our three cases, and the stylet was removed when the tube was passed through the vocal cord. Moreover, tracheal injury by stylet damages the anterior mucosal layers of the trachea because the stylet is curved anteriorly. However, two cases confirmed by fiberoptic bronchoscopy showed longitudinal rupture of the posterior membranous wall of the trachea. The posterior part of the trachea lacks cartilaginous support [6]. Secondly, many patients had higher pressure of cuff according to the retrospective survey of the hospital, where the operations of our cases were performed. Most cases presented over $50 \mathrm{cmH}_{2} \mathrm{O}$, and some even showed more than $100 \mathrm{cmH}_{2} \mathrm{O}$. Endotracheal tube cuff pressure should be in the range of 15$22 \mathrm{mmHg}$ to avoid complications related to underinflation (aspiration and leakage) and overinflation (tracheal wall ischemia, stenosis and tracheo-esophageal fistulae) [7]. Previous studies have suggested that the cuff pressure is usually underestimated by manual palpation. Braz et al. [8] observed cuff pressure exceeding $40 \mathrm{~cm} \mathrm{H}_{2} \mathrm{O}$ in $91 \%$ of PACU patients after anesthesia with nitrous oxide, $55 \%$ of ICU patients. Overinflation of an endotracheal tube (ETT) cuff may be prevented by use of a manometer to directly measure inflation pressure. Thirdly, nitrous oxide was used in all cases. Nitrous oxide lead to increased volume, and accidental overinflation can result from its diffusion in the cuff. Cuff pressures can be increased up to $90 \%$, even during relatively short procedures [9]. Fourthly, risk of tracheal injury increased more when overinflated cuff moved in the trachea. All cases had spine surgery in prone position, such that abrupt head and neck movement could not be ruled out because of two positional changes from intubation to extubation.

In the previous literatures published, the majority of case series showed not only female predominance, but the mean age over 50 years $[3-5,10,11]$. Some authors have suggested that post-intubation tracheal rupture may present more frequently in women because the pars membranosa is weaker in women than in men [12], and female tracheal diameters might be smaller in diameter than those of male, which makes women more vulnerable to cuff overinflation [10]. Short stature could also be a predisposing factor for tracheal rupture [10,11]. In our case series, all patients were female and older than 50 years, and their height was shorter than $160 \mathrm{~cm}$.

The clinical manifestations of tracheal injury include subcutaneous emphysema, mediastinal emphysema, pneumothorax, respiratory distress, and hemoptysis. Usually, they appear during surgery or in the immediate postoperative period [2]. Sometimes it does not occur till many hours later. Some authors reported that the time elapsed between the occurrence of the injury and the diagnosis was over $100 \mathrm{~h}[5,13]$. It is interesting to note that the subcutaneous emphysema is not only the most common symptom, but also a protective factor. Its presence alerts to the possible existence of tracheal rupture, consequently accelerating the procedures for its definitive diagnosis and the initiation of the appropriate treatment [11]. It is believed that delayed emphysema occurred with a possible small tear of the tracheal mucosa, allowing a slow and gradual leakage of a small amount of air [14]. In one of our cases, subcutaneous emphysema was detected only after 48 hours. The patient was improved after conservative treatment without 
surgical procedure. Fiberoptic bronchoscopy is believed to be the best subsequent method to confirm diagnosis and to determine the exact location and extent of the lesion. It should be done immediately after observing unexplained subcutaneous emphysema, which could indicate tracheal laceration.

Consensus of the treatment has not been established yet. Traditionally, early surgical repair has been the mainstay of treatment. However, recently there are more authors who opt to conservative treatment in patients with small ruptures, less than $2 \mathrm{~cm}$, and in selected patients with minimal, non-progressive symptoms and with no air leakage on spontaneous breathing $[3-5,15]$. Therefore, length and size of the lesion and clinical symptoms of the patient should be considered when planning a therapeutic option [11]. In our first two cases, surgical repair was chosen for treatment because the length of the lesion was more than $2 \mathrm{~cm}$ and symptoms were progressive. In the last case, conservative treatment was chosen because the symptoms were non-progressive and mild.

In summary, we presume that the tracheal injuries of 3 cases were caused by over-inflation of cuff and sudden movement of the tube by positional change. Therefore, to prevent overinflation, subtle management of cuff pressure by a manometer and minimized movement of the tube at positional change are necessary.

\section{References}

1. Prunet B, Lacroix G, Asencio Y, Cathelinaud O, Avaro JP, Goutorbe P. Iatrogenic post-intubation tracheal rupture treated conservatively without intubation: a case report. Cases J 2008; 1: 259.

2. Borasio P, Ardissone F, Chiampo G. Post-intubation tracheal rupture. A report on ten cases. Eur J Cardiothorac Surg 1997; 12: 98-100.

3. Carbognani P, Bobbio A, Cattelani L, Internullo E, Caporale D, Rusca M. Management of postintubation membranous tracheal rupture. Ann Thorac Surg 2004; 77: 406-9.

4. Marty-Ane CH, Picard E, Jonquet O, Mary H. Membranous tracheal rupture after endotracheal intubation. Ann Thorac Surg 1995; 60: 1367-71.

5. Jougon J, Ballester M, Choukroun E, Dubrez J, Reboul G, Velly JF. Conservative treatment for postintubation tracheobronchial rupture. Ann Thorac Surg 2000; 69: 216-20.

6. Lobato EB, Risley WP 3rd, Stoltzfus DP. Intraoperative management of distal tracheal rupture with selective bronchial intubation. J Clin Anesth 1997; 9: 155-8.

7. Jaber S, Kamel ME, Chanques G, Sebbane M, Cazottes S, Perrigault PF, et al. Endotracheal tube cuff pressure in intensive care unit: the need for pressure monitoring. Intensive Care Med 2007; 33: 917-8.

8. Braz JR, Navarro LH, Takata IH, Nascimento Junior P. Endotracheal tube cuff pressure: need for precise measurement. Sao Paulo Med J 1999; 117: 243-7.

9. Hasan A, Low DE, Ganado AL, Norton R, Watson DC. Tracheal rupture with disposable polyvinylchloride double-lumen endotracheal tubes. J Cardiothorac Vasc Anesth 1992; 6: 208-11.

10. Chen EH, Logman ZM, Glass PS, Bilfinger TV. A case of tracheal injury after emergent endotracheal intubation: a review of the literature and causalities. Anesth Analg 2001; 93: 1270-1.

11. Miñambres E, Burón J, Ballesteros MA, Llorca J, Muñoz P, GonzálezCastro A. Tracheal rupture after endotracheal intubation: a literature systematic review. Eur J Cardiothorac Surg 2009; 35: 105662.

12. Wagner A, Roeggla M, Hirschl MM, Roeggla G, Schreiber W, Sterz F. Tracheal rupture after emergency intubation during cardiopulmonary resuscitation. Resuscitation 1995; 30: 263-6.

13. Medina CR, Camargo Jde J, Felicetti JC, Machuca TN, Gomes Bde M, Melo IA. Post-intubation tracheal injury: report of three cases and literature review. J Bras Pneumol 2009; 35: 809-13.

14. Jo YY, Park WY, Choi E, Koo BN, Kil HK. Delayed detection of subcutaneous emphysema following routine endotracheal intubation -A case report. Korean J Anesthesiol 2010; 59: 220-3.

15. Conti M, Pougeoise M, Wurtz A, Porte H, Fourrier F, Ramon P, et al. Management of postintubation tracheobronchial ruptures. Chest 2006; 130: 412-8. 